\title{
Studies on the Potential of Waste Soda Lime Silica Glass in Glass Ionomer Cement Production
}

\author{
V. W. Francis Thoo, ${ }^{1}$ N. Zainuddin, ${ }^{1}$ K. A. Matori, ${ }^{2}$ and S. A. Abdullah ${ }^{1}$ \\ ${ }^{1}$ Department of Chemistry, Faculty of Science, Universiti Putra Malaysia, 43400 UPM Serdang, Selangor Darul Ehsan, Malaysia \\ ${ }^{2}$ Materials Synthesis and Characterization Laboratory, Institute of Advanced Technology, Universiti Putra Malaysia, \\ 43400 UPM Serdang, Selangor Darul Ehsan, Malaysia \\ Correspondence should be addressed to N. Zainuddin; hazlin@science.upm.edu.my
}

Received 8 April 2013; Revised 3 October 2013; Accepted 3 October 2013

Academic Editor: Luigi Nicolais

Copyright (c) 2013 V. W. Francis Thoo et al. This is an open access article distributed under the Creative Commons Attribution License, which permits unrestricted use, distribution, and reproduction in any medium, provided the original work is properly cited.

Glass ionomer cements (GIC) are produced through acid base reaction between calcium-fluoroaluminosilicate glass powder and polyacrylic acid (PAA). Soda lime silica glasses (SLS), mainly composed of silica $\left(\mathrm{SiO}_{2}\right)$, have been utilized in this study as the source of $\mathrm{SiO}_{2}$ for synthesis of $\mathrm{Ca}$-fluoroaluminosilicate glass. Therefore, the main objective of this study was to investigate the potential of SLS waste glass in producing GIC. Two glasses, GWX 1 (analytical grade $\mathrm{SiO}_{2}$ ) and GWX 2 (replacing $\mathrm{SiO}_{2}$ with waste SLS), were synthesized and then characterized using X-ray diffraction (XRD) and energy dispersive X-ray (EDX). Synthesized glasses were then used to produce GIC, in which the properties were characterized using Fourier transform infrared spectroscopy (FT-IR) and compressive test (from 1 to 28 days). XRD results showed that amorphous glass was produced by using SLS waste glass (GWX 2), which is similar to glass produced using analytical grade $\mathrm{SiO}_{2}$ (GWX 1). Results from FT-IR showed that the setting reaction of GWX 2 cements is slower compared to cement GWX 1. Compressive strengths for GWX 1 cements reached up to $76 \mathrm{MPa}$ at 28 days, whereas GWX 2 cements showed a slightly higher value, which is $80 \mathrm{MPa}$.

\section{Introduction}

Steele and his coworkers have reported that oral health problems would impact the quality of our life [1]. For instance, teeth problems affect food consumption and speech. Unhealthy teeth affect social interaction, appearance, diet, psychological status, and many more [2]. Hence, the finding and improvement of dental restorative materials are crucial.

In the early 1970s, Wilson and Kent had invented glassionomer cements (GICs) or polyalkenoate cements following ISO standard as a tooth restorative material in the English Laboratory of the Government Chemist [3]. GICs have been used clinically for more than 30 years providing a more convincing and simpler handling procedure compared to other materials. GICs are widely used in various clinical applications: posterior and anterior teeth fillings, luting agents, sealants materials, linings, cements for orthodontic brackets, root canal fillings, and so forth. There are advantages of GICs compared to other dental materials. Amalgam, a widely used dental material, has a controversial issue because of the concern about the toxicity of mercury. Dental casting alloy, which has excellent physical properties, is expensive and might cause allergic reaction to a certain group of patients. In addition, amalgam and dental casting alloys with different colours to teeth are not preferable to certain patients. Resin composite, a dental material which has similar color to teeth and with great physical properties is one of the most ideal dental material, however it contain bisphenol A which might cause allergy and estrogenic effect [4].

Glass for GICs is produced by melting silica $\left(\mathrm{SiO}_{2}\right)$, alumina $\left(\mathrm{Al}_{2} \mathrm{O}_{3}\right)$, metal fluorides, metal oxides, and metal phosphate in certain ratio and conditions can overcome disadvantages caused by other dental materials mentioned above. GICs have the ability to adhere to teeth structure in our mouth under moist condition. Long-lasting fluoride released from the material is also an advantage, which prevents forming caries [5]. By manipulating the powder to liquid ratio, we can produce cements with different physical 
properties, which can be applied in different types of teeth restorations.

GICs are produced under acid and base reaction by mixing glass powder with polyacid in aqueous state. The setting reaction begins with the release of $\mathrm{H}^{+}$ions from acid, which then hydrolyze the glass containing aluminiumoxygen-silicon network. This action causes the glass to release metal ions (aluminium and calcium cations) and also leads to the release of anions, such as fluoride [6]. Metal ions would be chelated by the carboxylate group from acid to form crosslinkages in polymer chains [7].

Waste glass is a large component of household and industry, for example, containers for beverage and food as well as the commodity items. One of the significant waste glasses is SLS waste glass. Since the major chemical compositions of SLS waste glass are basically $\mathrm{SiO}_{2}(73.9 \%)$ and $\mathrm{CaO}$ (11.2 wt \%) [8], it can be used as a source of silica for glass in GICs. SLS waste glasses have been used in other fields of study and they give good mechanical properties. For instance, Tucci and his coworkers have reported that compressive strength of their stoneware tile increased by adding SLS glass [9]. Besides, SLS waste glass also has been used in producing vitreous ceramics [10].

In this research, the potential of SLS waste glass as the main source of $\mathrm{SiO}_{2}$ for the synthesis of aluminosilicate glass was studied. Furthermore, this glass was used in the synthesis of GICs and the setting reactions as well as the compressive strength of GICs were determined.

\section{Experimental Section}

2.1. Materials. Analytical grade of calcium carbonate anhydrous $>99 \%$ purity (Fisher Scientific, USA), aluminum oxide 99.99\% (Fisher Scientific, USA), silicon dioxide 99.99\% (Sigma-Aldrich, USA), phosphorus pentoxide $>99 \%$ (Acros Organics, USA), and calcium fluoride $>99.99 \%$ (SigmaAldrich, USA) were used for cements preparation (GWX 1). For GWX 2 glass, silicon dioxide was replaced with soda lime silica waste bottles obtained from local restaurant in Selangor, Malaysia. Medical grade freeze-dried polyacrylic acid, PAA (Mw 30,000), was supplied by Advance Healthcare, Kent, UK.

2.2. Synthesis of GWX 1 and GWX 2 Glasses. Two types of glass, GWX 1 and GWX 2, with similar composition using different sources of $\mathrm{SiO}_{2}$ (analytical grade $\mathrm{SiO}_{2}$ (GWX 1) and SLS waste bottles (GWX 2)) were synthesized for this study. The basic compositions for melting these glasses were alumina, calcium oxide, silica, phosphorus pentoxide, and calcium fluoride. Weight percentages of each composition were based on a previous study, which were $19.5 \%$ alumina, $19.5 \%$ calcium oxide, $26 \%$ silica, $20 \%$ phosphorus pentoxide, and $15 \%$ calcium fluoride [11]. The raw materials were mixed homogeneously and then melted at $1500^{\circ} \mathrm{C}$ for 2 hours. When molten glasses were formed, they were rapidly quenched in water to avoid crystallization and phase separation. The synthesized glasses were then ground and sieved to $\leq 45 \mu \mathrm{m}$ particle size. Glasses produced were then characterized using XRD.

2.3. Energy Dispersive X-Ray (EDX). The elemental analysis of the SLS waste glass was performed using an energy dispersive X-ray analyser (FEI-Quanta 200, The Netherlands) directly connected to the SEM operated in environmental mode at $15 \mathrm{kV}$ with relative humidity of $96 \%-99 \%$.

2.4. X-Ray Diffraction (XRD). XRD was used to identify the phase of the glasses. Patterns of XRD were obtained from PANalytical X'PERT PRO PW 3040 model by continuous scanning at the rate of $2^{\circ} /$ minute in the $2 \theta$ range of $4^{\circ}$ to $90^{\circ}$.

2.5. Cements Preparation. The cements were prepared by thoroughly mixing the glass $(\leq 45 \mu \mathrm{m})$ together with polyacrylic acid and water with the ratio of $3: 1: 1$ by weight percentage. The cements were then placed into moulds and into incubator at $37^{\circ} \mathrm{C}$ for 1 hour before being transferred into deionized water. For cements less with than 1 hour ageing time, liquid nitrogen and ethanol were used to terminate the reaction and dehydrate the cements. All cements were prepared according to ISO9917-1: 2007 Dentistry Water Based Cements Part 1: Powder/liquid acid-base cements 2007.

2.6. Compressive Strength. Compressive strength $\left(\sigma_{c}\right)$ of the cements was done according to ISO9917 in the dimension of $6.0 \mathrm{~mm} \times 4.0 \mathrm{~mm}$ cylinder. Cement samples were tested at 1 , 7 , and 28 days. The test was performed using Instron 4082 Universal Testing Machine with $1 \mathrm{kN}$ load cell at a crosshead of $1 \mathrm{~mm} / \mathrm{min}^{-1}$.

2.7. Fourier Transforms Infrared Spectroscopy (FT-IR). FT-IR was used to study setting reaction of the cements at different ageing times: 5 minutes, 15 minutes, 30 minutes, 1 hour, 6 hours, 1 day, 7 days, and 28 days. The spectra were obtained from ATR (attenuated total reflectance) method on Perkin Elmer Spectrum 100 Series in the range of $4000-200 \mathrm{~cm}^{-1}$.

\section{Results and Discussion}

\subsection{Characterization of Glass}

3.1.1. Energy Dispersive X-Ray Microanalysis (EDX). The compositions by weight of SLS waste glass are $\mathrm{SiO}_{2} 73.42 \%$, $\mathrm{Al}_{2} \mathrm{O}_{3} 3.12 \%, \mathrm{MgO} 1.92 \%, \mathrm{CaO} 14.42 \%$, and $\mathrm{Na}_{2} \mathrm{O} 8.6 \%$. The silica content in the SLS waste bottle is sufficient to produce aluminosilicate glass for GIC. Other elements such as sodium and magnesium are reported to be suitable in forming dental glass and do not cause toxicity to human body [4].

3.1.2. X-Ray Diffraction (XRD). XRD is an important method to determine the phase of the glasses. There is no sharp peak observed in Figure 1 for both glasses (produced from analytical grade $\mathrm{SiO}_{2}$ or waste SLS glass bottle). This indicates that the glasses produced from 2 different types of silica are in amorphous phase. 


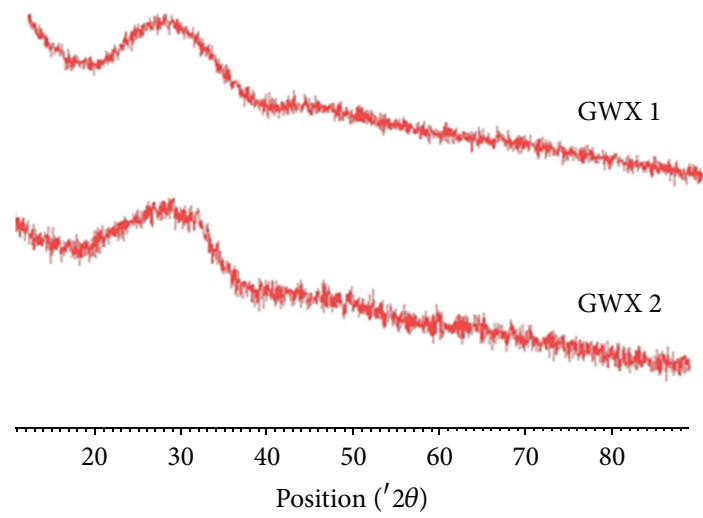

FIGURE 1: XRD patterns for GWX1 (analytical grade $\mathrm{SiO}_{2}$ ) and GWX 2 (SLS waste glass).

\subsection{Characterization of GICs}

3.2.1. Compressive Strength. Compressive test was carried out on 8 samples and it is calculated using the formula

$$
\sigma_{c}=\frac{F}{\pi r^{2}}
$$

where $\sigma_{c}$ is the compressive strength, $F$ is the force, and $r$ is the radius of the cements cylinder.

The compressive strength is the result of maturing and hardening of the GICs cements. Compressive strength is said to be directly proportional to its ageing time; hence, it will increase with time.

Figure 2 shows the result of compressive strength of both GWX 1 and GWX 2 cements. Based on the results, compressive strength for both cements of different materials increased from 1 day to 28 days ageing time. Both cements showed a significant increase from 1 day to 7 days but the strength only slightly increased from 7 to 28 days ageing time. At 1 day, the compressive strength of GWX 1 is $69 \mathrm{MPa}$, while GWX 2 is only $59 \mathrm{MPa}$. The GWX 2 cement has lower compressive strength at 1 day ageing time due to the presence of $\mathrm{Na}_{2} \mathrm{O}$ in SLS waste glass. It is believed that $\mathrm{Na}$ will form sodium polyacrylate salt with PAA, hence inhibiting the cross-linking reaction of PAA with $\mathrm{Al}^{3+}$ and $\mathrm{Ca}^{2+}[12]$. However, the compressive strength for both cements increased to $74 \mathrm{MPa}$ for GWX 1 and $77 \mathrm{MPa}$ for GWX 2 at 7 days ageing time. At 28 days, both GWX 1 and GWX 2 cements have slightly increased to $77 \mathrm{MPa}$ and $80 \mathrm{MPa}$, respectively. The results showed that waste SLS glass is suitable to be used as raw material in producing GICs cements, since the compressive strength of the cement from GWX 2 can reach a similar value to GWX 1. The results show no significant difference on compressive strength tests between 7 days and 28 days for both cements. In addition, results from EDX show that the percentage by weight of aluminium $\left(\mathrm{Al}^{3+}\right)$ in the waste SLS waste glass is $3.12 \%$ which is important in depolymerising the silicate network by facilitating acid degradability. Degradability of acid forms aluminium-polyacrylic acid complexes during the setting reaction, which gives a slightly higher compressive strength on the 7 and 28 days for GWX 2 cements [13].

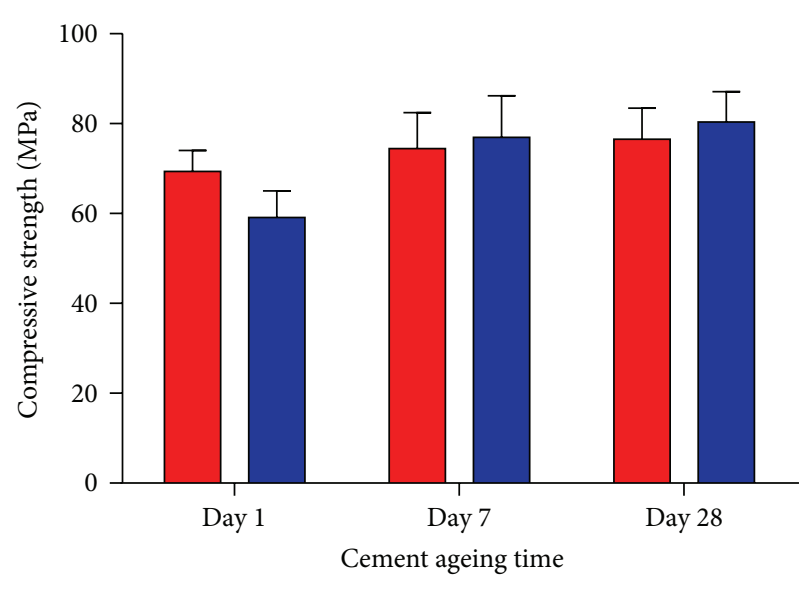

GWX 1
GWX 2

FIgURE 2: The compressive strength of GPCs for GWX 1 and GWX 2 at 1,7 , and 28 days.

3.2.2. Setting Reaction. FT-IR was used to follow the setting reaction of both GICs. The setting of cements is based on cross-linking reaction of $\mathrm{COOH}$ with metal ions from glass and hardening process of $\mathrm{Si}-\mathrm{OH}$ to $\mathrm{Si}-\mathrm{O}-\mathrm{Si}$ in cement. Figure 3(a) shows the infrared spectra of GICs from GWX 1 glass at 5 minutes to 28 days ageing time. At 5 minutes ageing time, the $\mathrm{COOH}$ band for GWX 1 cements can be observed clearly at $1730 \mathrm{~cm}^{-1}$ with a small band of $\mathrm{COO}^{-} \mathrm{M}^{+}$ at $1620 \mathrm{~cm}^{-1}$. The intensity of the $\mathrm{COO}^{-} \mathrm{M}^{+}$band increases with ageing time, while the intensity of $\mathrm{COOH}$ gets lower. This shows that the cross-linking reaction of $\mathrm{COOH}$ with the metal ions $\left(\mathrm{Al}^{3+}\right.$ and $\left.\mathrm{Ca}^{2+}\right)$ proceeds with the ageing time $[14,15]$.

A similar trend can be found for GICs from SLS waste glass (Figure 3(b)). However, the rate of cross-linking reaction in GIC from SLS waste glass is slower compared to GIC from pure silica. This can be seen by comparing both GWX 1 and GWX 2 setting reactions in Figures 3(a) and 3(b), where $\mathrm{COOH}$ and $\mathrm{COO}^{-} \mathrm{M}^{+}$bands appear at equal intensity at different ageing times. For GIC from pure silica, equal intensity of $\mathrm{COOH}$ and $\mathrm{COO}^{-} \mathrm{M}^{+}$is at 15 minutes ageing time, whereas for GIC from SLS waste glass it can be seen at 1 hour and 1 day ageing time. This observation can explain why the compressive strength of GIC from SLS waste glass is lower than pure silica glass at 1 day ageing time. However, at 28 days ageing time, both GICs showed a similar trend, where the COOH band is not clearly observed anymore.

The other bands that can be observed in the spectra were $\mathrm{Si}-\mathrm{O}-\mathrm{Si}$ and $\mathrm{Si}-\mathrm{OH}$ bands between $1200 \mathrm{~cm}^{-1}$ and $800 \mathrm{~cm}^{-1}$. $\mathrm{Si}-\mathrm{OH}$ was observed at $943.25 \mathrm{~cm}^{-1}$ due to $\mathrm{Si}-\mathrm{O}(\mathrm{Si})$ stretching vibration [15]. At 5 minutes setting time, the intensity of Si$\mathrm{OH}$ was higher than of $\mathrm{Si}-\mathrm{O}-\mathrm{Si}$. The $\mathrm{Si}-\mathrm{OH}$ peak began to decrease at 30 minutes and $\mathrm{Si}-\mathrm{O}-\mathrm{Si}$ peak began to appear. The intensity of Si-O-Si began to increase at 1 hour and it was much higher than of Si-OH [14-16]. 


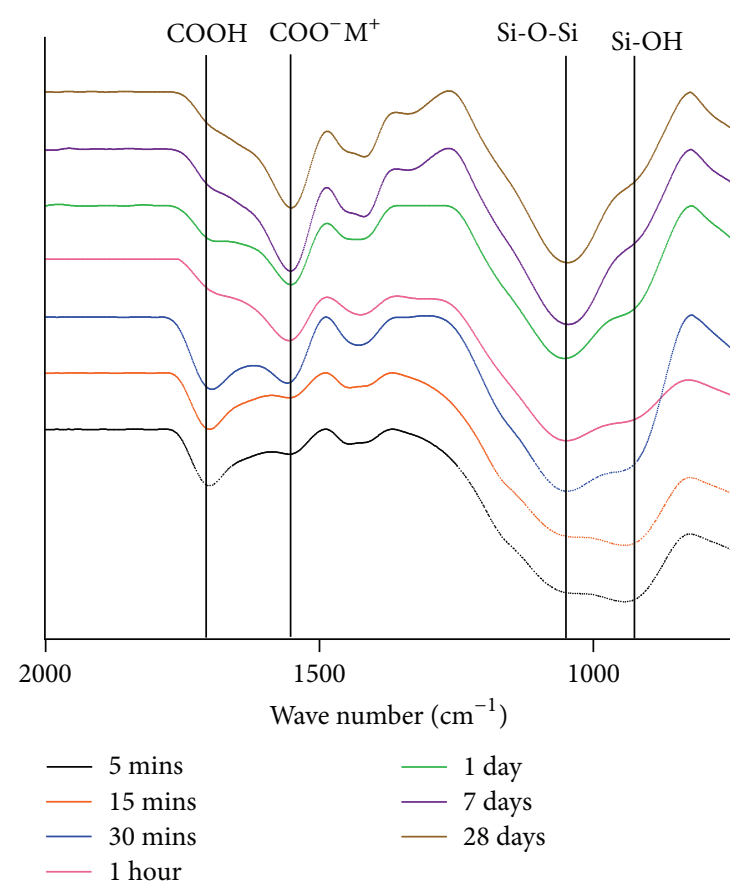

(a)

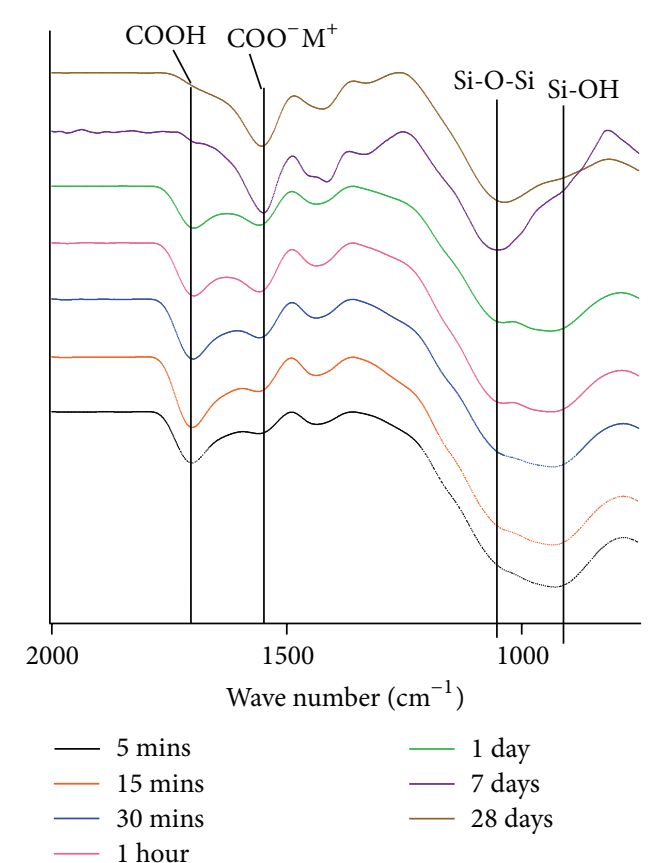

(b)

FIGURE 3: Infrared spectra for GWX 1 and GWX 2.

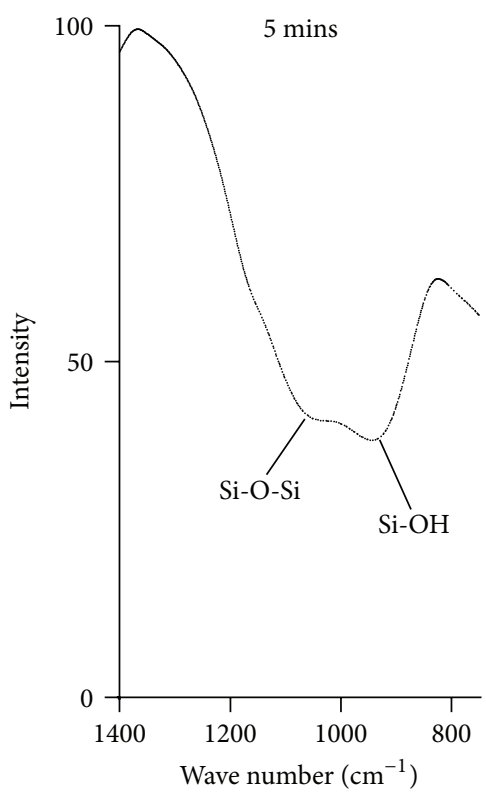

(a)

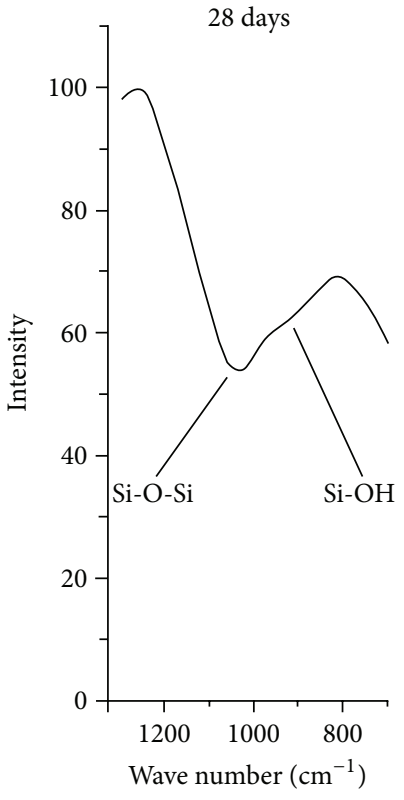

(b)

FIgURE 4: Infrared spectra of GWX 1 at 5 minutes and 28 days ageing time.

Polymerization of $\mathrm{Si}-\mathrm{OH}$ to $\mathrm{Si}-\mathrm{O}-\mathrm{Si}$ also takes place in the setting of the cement. As we can observe from Figure 4, the intensity of $\mathrm{Si}-\mathrm{OH}$ band is lower at 28 days compared to 5 minutes, while the intensity of Si-O-Si band is higher at 28 days of ageing time than earlier ageing times. The increase in intensity can be explained by the deformation of $\mathrm{Si}-\mathrm{OH}$
[13-15]. The silica networks of the glass undergo changes as $\mathrm{Si}-\mathrm{O}-\mathrm{Si}$ bond formed in cement. $\mathrm{Si}$ atom was tetrahedrally coordinated by oxygen atom, which was attached to $\mathrm{Al}$ atoms. $\mathrm{H}^{+}$ion will replace $\mathrm{Al}$ atoms as the glasses were introduced to PAA. As the ageing time increased, the water molecules were eliminated and formed $\mathrm{Si}-\mathrm{O}-\mathrm{Si}$ bond in the cement. This also 


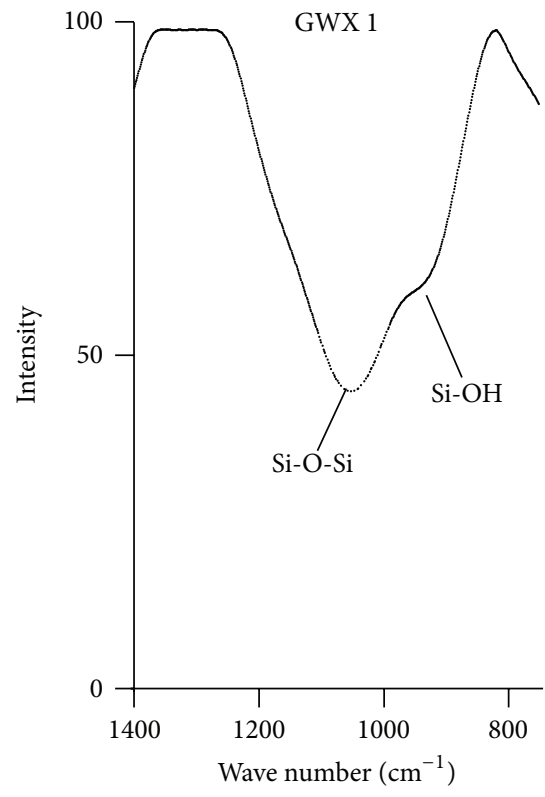

(a)

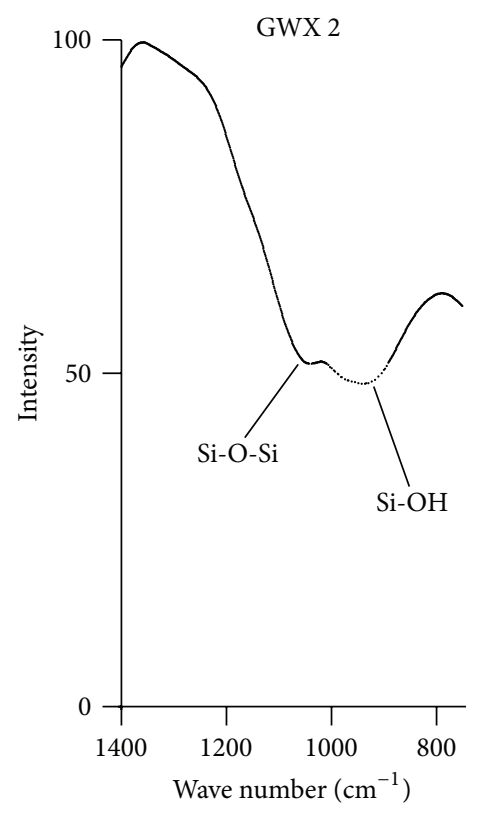

(b)

FIGURE 5: Infrared spectra of GWX 1 and GWX 2 cements at 1 day ageing time.

explains the increasing of compressive strength as the ageing time increased.

Figure 5 shows the infrared spectra of both GICs at 1 day ageing time. Based on both spectra, the intensity of $\mathrm{Si}-$ $\mathrm{O}-\mathrm{Si}$ band for pure cement is higher than of SLS cement. This explains the reason for higher compressive strength for pure cement at 1 day setting time than SLS cement. Formation of Si-O-Si bond in cement can also contribute to high compressive strength. Besides, the presence of sodium in GWX 2 (SLS waste cement) may influence the cement properties. A previous study suggested that sodium ions will compete with aluminum and calcium ions for carboxylate groups in polyacid chains and it hence inhibits the formation of cross-linking in the early stage of ageing [12]. This is hence explaining why GWX 2 gives a slower setting reaction compared to GWX 1 cements. However, the influence of sodium is less for 7 days and 28 days ageing times.

Degree of cross-linking (DCL) of the polymeric acid can be calculated using the formula below:

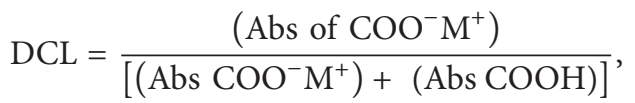

where $\mathrm{Abs}$ is the absorbance at each wave number. The change of DCL had been plotted in Figure 6. Both DCL showed increment as the ageing time increased. It is well known that the hardening of GPCs is due to the cross-linking of $\mathrm{COOH}$ with metal ions. From the result of DCL, the compressive strength for both cements increases as the value of DCL increased. Based on Figure 2, the compressive strength at 1 day for cement from pure silica was greater than for cements from SLS waste glass. This was proven by the value of DCL. However, the DCL value for 7 and 28 days for SLS cement was slightly lower compared to DCL value for pure cement.

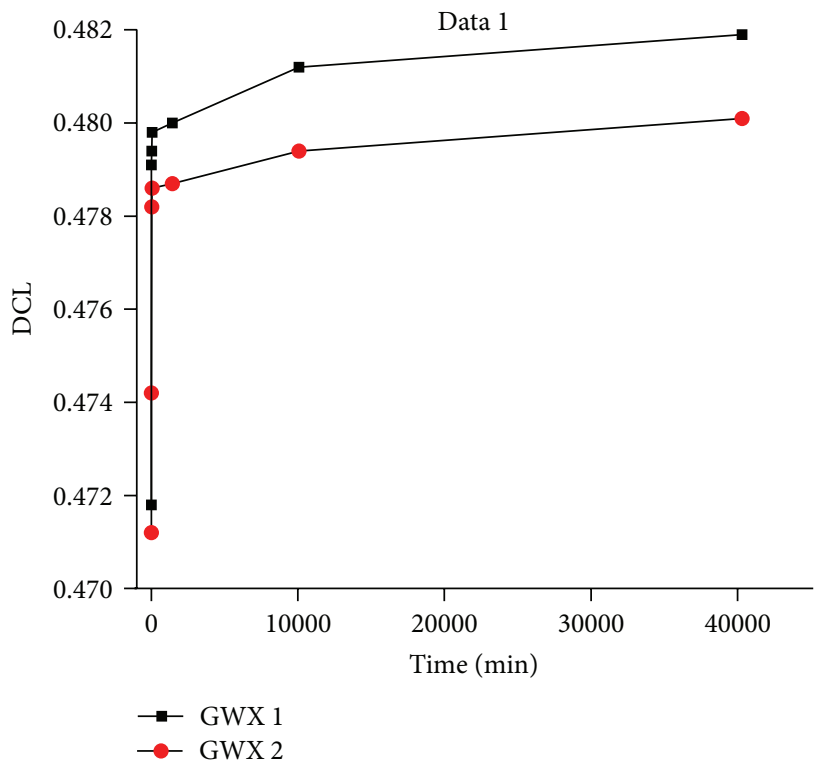

FIGURE 6: Change in the degree of cross-linking (DCL) of both GICs.

This is in contrast with our compressive strength result. It is worth mentioning that the hardening of GICs is not only due to cross-linking of $\mathrm{COOH}$ to metal ions but also due to polymerization of $\mathrm{Si}-\mathrm{OH}$ to $\mathrm{Si}-\mathrm{O}-\mathrm{Si}$. Moreover, the difference of degree of cross-linking for both GWX 1 and GWX 2 cements is very small (less than 0.005).

\section{Conclusions}

This paper has revealed the potential of SLS waste glass in dental restorative field. SLS waste glass had been utilized 
as one of the raw materials for the synthesis of GIC. High percentage of silica in SLS waste glass gives a great source as raw material in production of glass for dental cement. SLS waste glass has been successfully incorporated as part of glass phase in GIC as illustrated with the absence of sharp diffraction lines observed in XRD pattern.

GIC from SLS waste glass shows similar trends in setting reaction with GIC from analytical grade $\mathrm{SiO}_{2}$ as indicated in FT-IR spectra. GIC from SLS waste glass (GWX 2) shows a steady establishment of cross-linking even though it exhibits slower cross-linking rate at initial period compared to GWX 1. This has strongly suggested that SLS waste glass is suitable in making GIC.

From the results of compressive strength, both GWX 1 and GWX 2 cements show an increased physical strength throughout the ageing period. Both of their results are in a good agreement with setting reaction trend from FT-IR, which suggests that setting reaction continues throughout the experimental period.

In conclusion, similar trends of setting reaction and compressive strength for both GWX 1 and GWX 2 in the study strongly suggest that SLS waste glass is suitable to be utilized in production of GIC for dental application.

\section{Conflict of Interests}

The authors hereby declare that there is no conflict of interests with the trademarks mentioned in this paper.

\section{References}

[1] J. G. Steele, A. E. Sanders, G. D. Slade et al., "How do age and tooth loss affect oral health impacts and quality of life? a study comparing two national samples," Community Dentistry and Oral Epidemiology, vol. 32, no. 2, pp. 107-114, 2004.

[2] J. John, S. A. Mani, and Y. Azizah, "Oral health care in the elderly population in Malaysia-a review," Medical Journal of Malaysia, vol. 59, no. 3, pp. 433-438, 2004.

[3] B. E. Kent, B. G. Lewis, and A. D. Wilson, "The properties of a glass ionomer cement," British Dental Journal, vol. 135, no. 7, pp. 322-326, 1973.

[4] C. L. Davidson and I. A. Mjor, Advances in Glass-Ionomer Cements, Quintessence, Chicago, Ill, USA, 1999.

[5] S.-H. Park and K.-Y. Kim, "The anticariogenic effect of fluoride in primer, bonding agent, and composite resin in the cavosurface enamel area," Operative Dentistry, vol. 22, no. 3, pp. 115-120, 1997.

[6] A. D. Wilson and S. Crisp, "Ionomer cements," British Polymer Journal, vol. 7, no. 5, pp. 279-296, 1975.

[7] A. D. Wilson, “The chemistry of dental cements," Chemical Society Reviews, vol. 7, no. 2, pp. 265-296, 1978.

[8] B. H. W. S. D. Jong, Ullmann's Encyclopedia of Industrial Chemistry, VCH, Weinheim, Germany, 1989.

[9] A. Tucci, L. Esposito, E. Rastelli, C. Palmonari, and E. Rambaldi, "Use of soda-lime scrap-glass as a fluxing agent in a porcelain stoneware tile mix," Journal of the European Ceramic Society, vol. 24, no. 1, pp. 83-92, 2004.
[10] N. Marinoni, "Effects of soda-lime-silica waste glass on mullite formation kinetics and micro-structures development in vitreous ceramics," Journal of Environmental Management, vol. 124, pp. 100-107, 2013.

[11] N. Zainuddin, N. Karpukhina, R. G. Hill, and R. V. Law, “A longterm study on the setting reaction of glass ionomer cements by 27Al MAS-NMR spectroscopy," Dental Materials, vol. 25, no. 3, pp. 290-295, 2009.

[12] E. De Barra and R. G. Hill, "Influence of alkali metal ions on the fracture properties of glass polyalkenoate (ionomer) cements," Biomaterials, vol. 19, no. 6, pp. 495-502, 1998.

[13] J. W. Nicholson, "Chemistry of glass-ionomer cements: a review," Biomaterials, vol. 19, no. 6, pp. 485-494, 1998.

[14] S. K. Tomlinson, O. R. Ghita, R. M. Hooper, and K. E. Evans, "Investigation of the dual setting mechanism of a novel dental cement using infrared spectroscopy," Vibrational Spectroscopy, vol. 45, no. 1, pp. 10-17, 2007.

[15] S. Matsuya, T. Maeda, and M. Ohta, "IR and NMR analyses of hardening and maturation of glass-ionomer cement," Journal of Dental Research, vol. 75, no. 12, pp. 1920-1927, 1996.

[16] E. A. P. De Maeyer, R. M. H. Verbeeck, and C. W. J. Vercruysse, "Infrared spectrometric study of acid-degradable glasses," Journal of Dental Research, vol. 81, no. 8, pp. 552-555, 2002. 

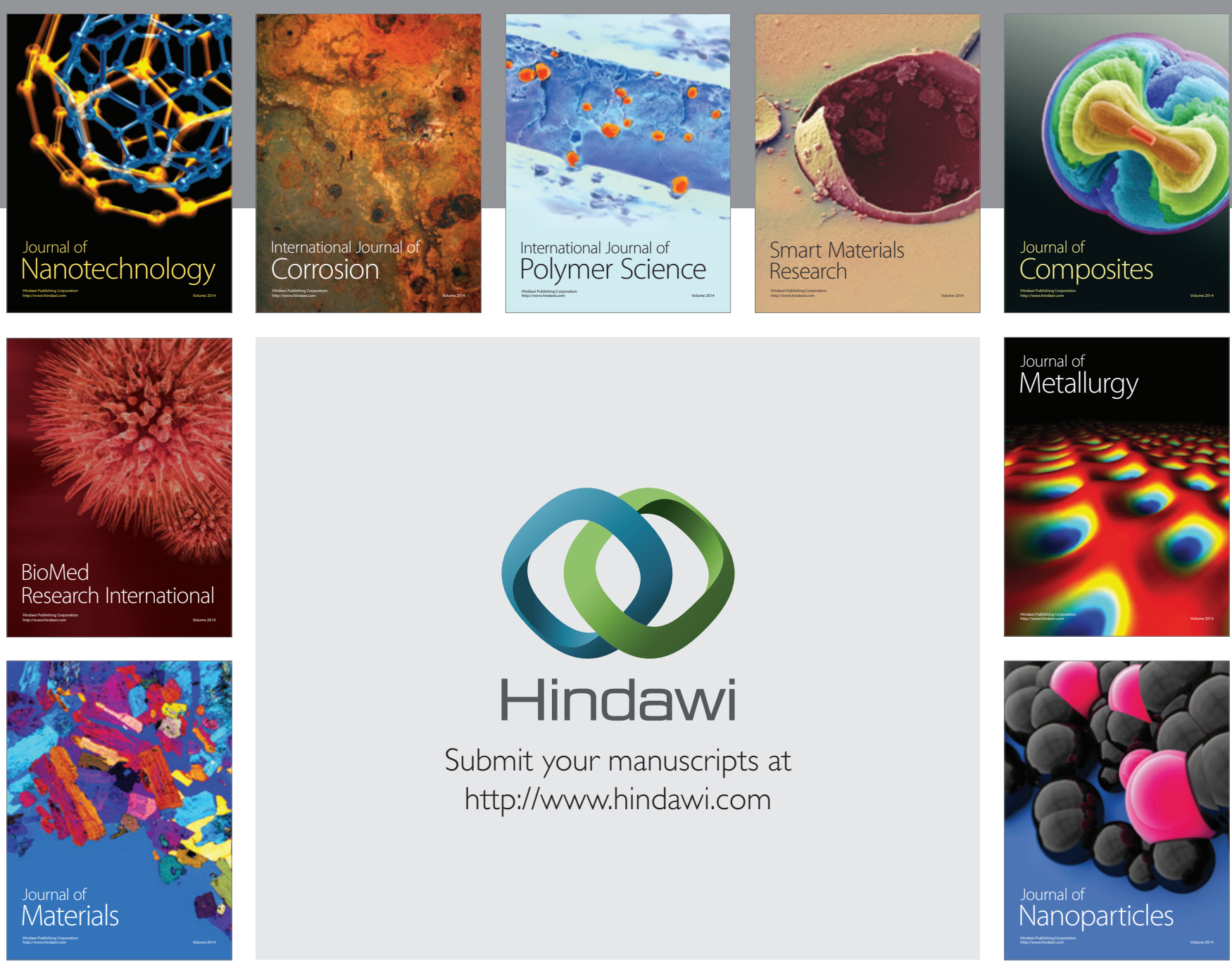

Submit your manuscripts at http://www.hindawi.com
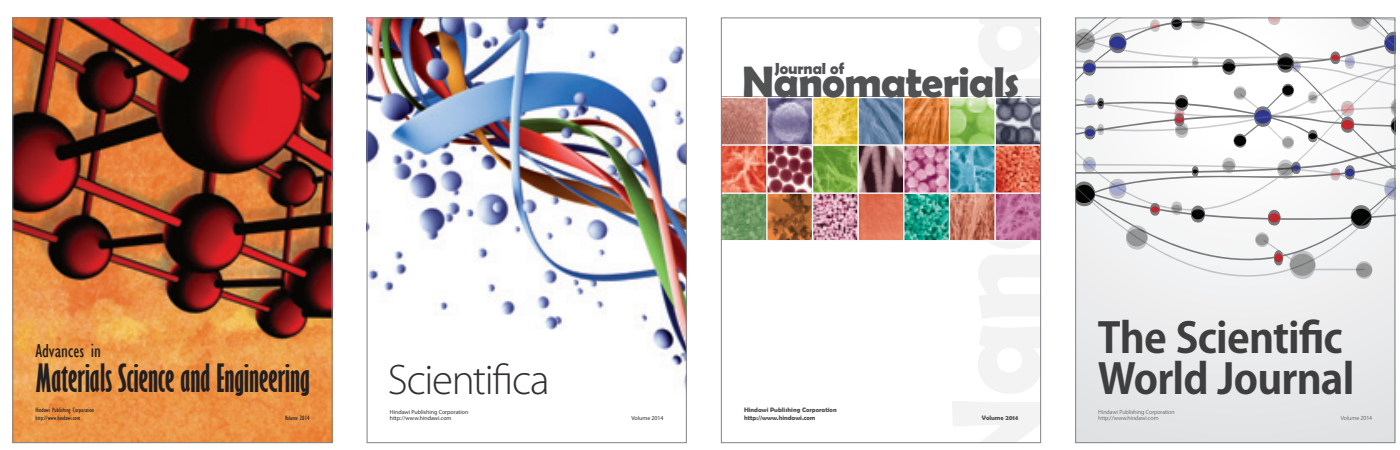

\section{The Scientific World Journal}
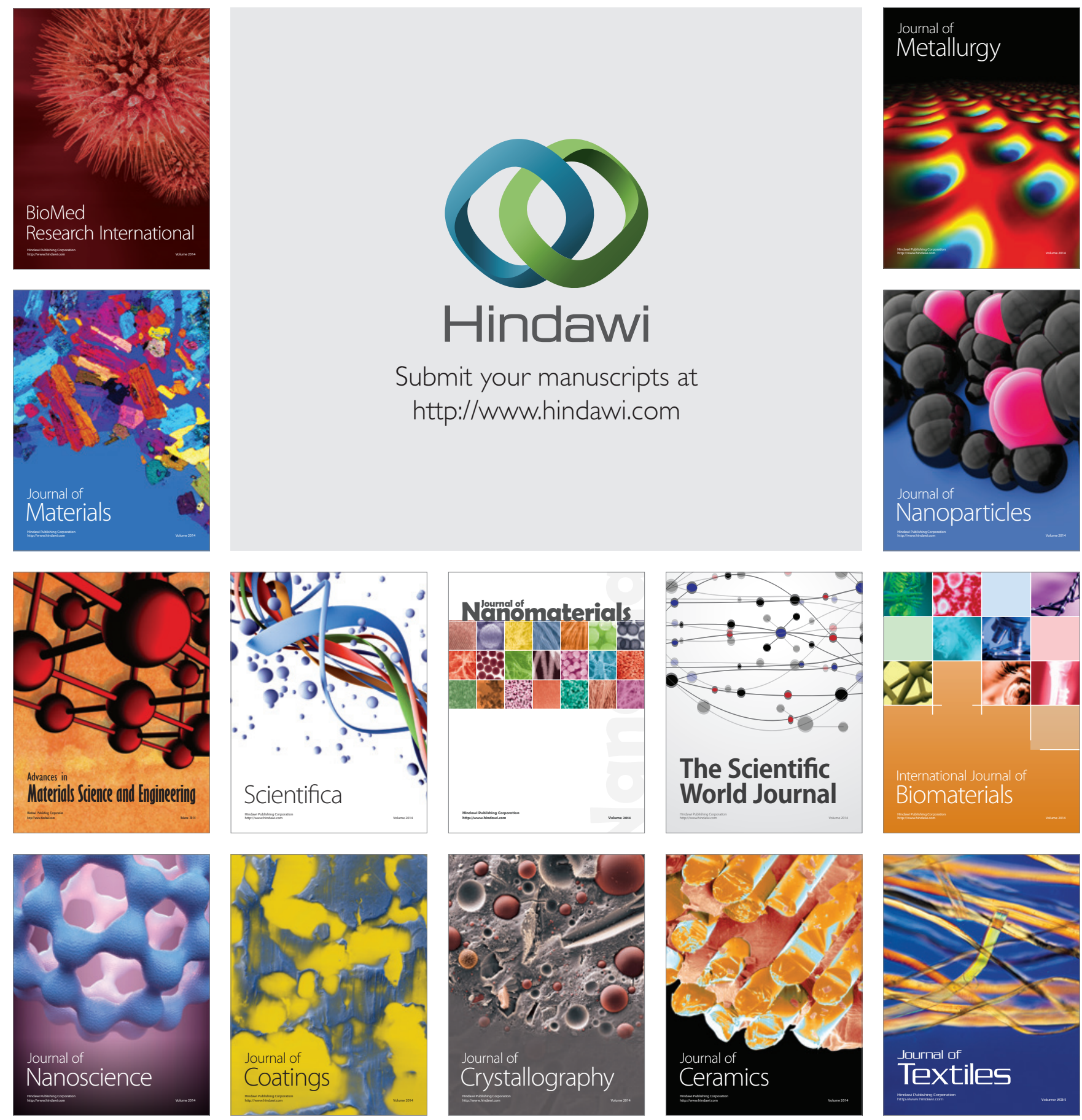